\title{
USGS Hydro-Climatic Data Network 2009 (HCDN-2009)
}

\section{Introduction}

The U.S. Geological Survey's (USGS) Hydro-Climatic Data Network (HCDN) is a subset of all USGS streamgages for which the streamflow primarily reflects prevailing meteorological conditions for specified years. These stations were screened to exclude sites where human activities, such as artificial diversions, storage, and other activities in the drainage basin or the stream channel, affect the natural flow of the watercourse. In addition, sites were included in the network because their record length was sufficiently long for analysis of patterns in streamflow over time. The purpose of the network is to provide a streamflow dataset suitable for analyzing hydrologic variations and trends in a climatic context. When originally published, the network was composed of 1,659 stations (Slack and Landwehr, 1992) for which the years of primarily "natural" flow were identified. Since then, data from the HCDN have been widely used and cited in climate-related hydrologic investigations of the United States. The network has also served as a model for establishing climate-sensitive streamgage networks in other countries around the world.

After nearly two decades of use without undergoing a systematic revalidation, questions have arisen as to whether many of the original stations still maintain their climatesensitive status or even remain operational, as some are known to have closed. Some watersheds had been altered to the point that stations no longer meet the minimal disturbance criteria set forth in the original HCDN report. In addition, some sites that did not qualify as HCDN sites in 1988 (the last year of data evaluation) because their records were too short now have sufficiently long streamflow records for climate-sensitivity studies. Accordingly, a review of the existing network was initiated in 2009 in order to drop old stations and add new ones as appropriate.

\section{Related Efforts: GAGES Reference Sites}

As the HCDN review began, the USGS National Water-Quality Assessment (NAWQA) Program completed an analysis of gaged drainage basins to identify reference sites in the conterminous United States (Falcone and others, 2010) primarily for determining natural streamflows relevant to aquatic ecosystems and for evaluating natural versus altered flow conditions. The resulting database, referred to as GAGES (Geospatial Attributes of Gages for Evaluating Streamflow), incorporated basin attributes for 6,785 USGS streamgages, and their upstream drainage basins, with at least 20 years of complete-year flow record during the period 1950-2007. Basin attributes include the percentage of basin area in various land cover types (urban, agriculture, forest, and so on); impervious surface; population density and road density; climate, geology, topography, and soil characteristics; dam storage; percentage of streams coded as canals or pipelines; and freshwater withdrawals in the basins. The database also includes comments from the State-based USGS Annual Water Data Reports (http://wdr.water.usgs.gov/) regarding human-induced modifications and diversions that might affect streamflow.

Reference sites in the GAGES database were identified by comparison with other gages within aggregated ecoregions (Falcone and others, 2010). In the original (2010) GAGES database, 1,512 streamgages were identified as being in current "reference" condition, or minimally affected by direct human activities. For a gaged basin to receive a reference designation, the watershed had to meet three primary criteria:

1. Hydrologic disturbance of the watershed was less than at least 75 percent of all other gaged watersheds in its region. Disturbance was determined with an index that included geospatial measures of reservoir storage, dam locations and density, freshwater withdrawal, road density, and the U.S. Environmental Protection Agency's National Pollutant Discharge Elimination System (NPDES) discharges. The disturbance index was calculated for all gaged watersheds and ranked within each of nine major regions. Watersheds that were in the lowest quartile of the disturbance index were given priority consideration as having potential reference quality.

2. The USGS Annual Water Data Reports did not identify the presence of "regulated" streamflows. Some sites considered to have minor modifications were retained.

3. The watershed passed a visual screen using satellite imagery (typically Google Earth) of the entire watershed for the presence of human activities that suggested flow diversions, groundwater withdrawal, and other factors known to influence natural streamflows.

The screening of reference streamgages was not targeted to a specific attribute of streamflow. For example, human activities in a basin may have no net impact on mean annual flow but may influence the timing and duration of specific flow magnitudes. 
Under such conditions, the site would be excluded. The intent was to identify gaged sites with all attributes of streamflow in natural or least-disturbed condition. It is important to note that the GAGES reference sites were derived independently of the original HCDN; that is, whether a station was part of the original HCDN was not considered in the classification process. In 2011, NAWQA released an updated GAGES-II database (Falcone, 2011). This new version contains data for 9,322 streamgages, of which 2,057 are identified as reference gages.

\section{HCDN-2009 Sites}

Given the close correspondence between HCDN and GAGES reference site criteria, with the latter typically being more stringent than those originally established for the HCDN, the USGS decided to make the updated HCDN a subset of the GAGES-II reference network. Reinforcing this decision was a desire to avoid potential conflicts arising from differences in the stations listed in two similar, though distinct, reference networks. Thus, the updated network is referred to as HCDN-2009 and is so designated in the GAGES-II database (http://water.usgs.gov/GIS/metadata/usgswrd/XML/ gagesII_Sept2011.xml).

Stations included in HCDN-2009 meet the following criteria: (1) they are identified as being in current "reference" condition according to the GAGES-II classification; (2) they have at least 20 years of complete and continuous discharge record through water year 2009; (3) they have less than 5 percent impervious surface area as measured using the Federal National Land Cover Data (NLCD) 2006; and (4) they were not eliminated during a review by participating State USGS Water Science Centers. The designation "HCDN-2009" signifies that the data from these stations have been quality assured and validated as conforming to the HCDN criteria through water year 2009. Because the HCDN-2009 is drawn from the GAGES-II database the HCDN data adhere to all the criteria that were applied to the GAGES database, which notably include the requirement that watersheds are contained within

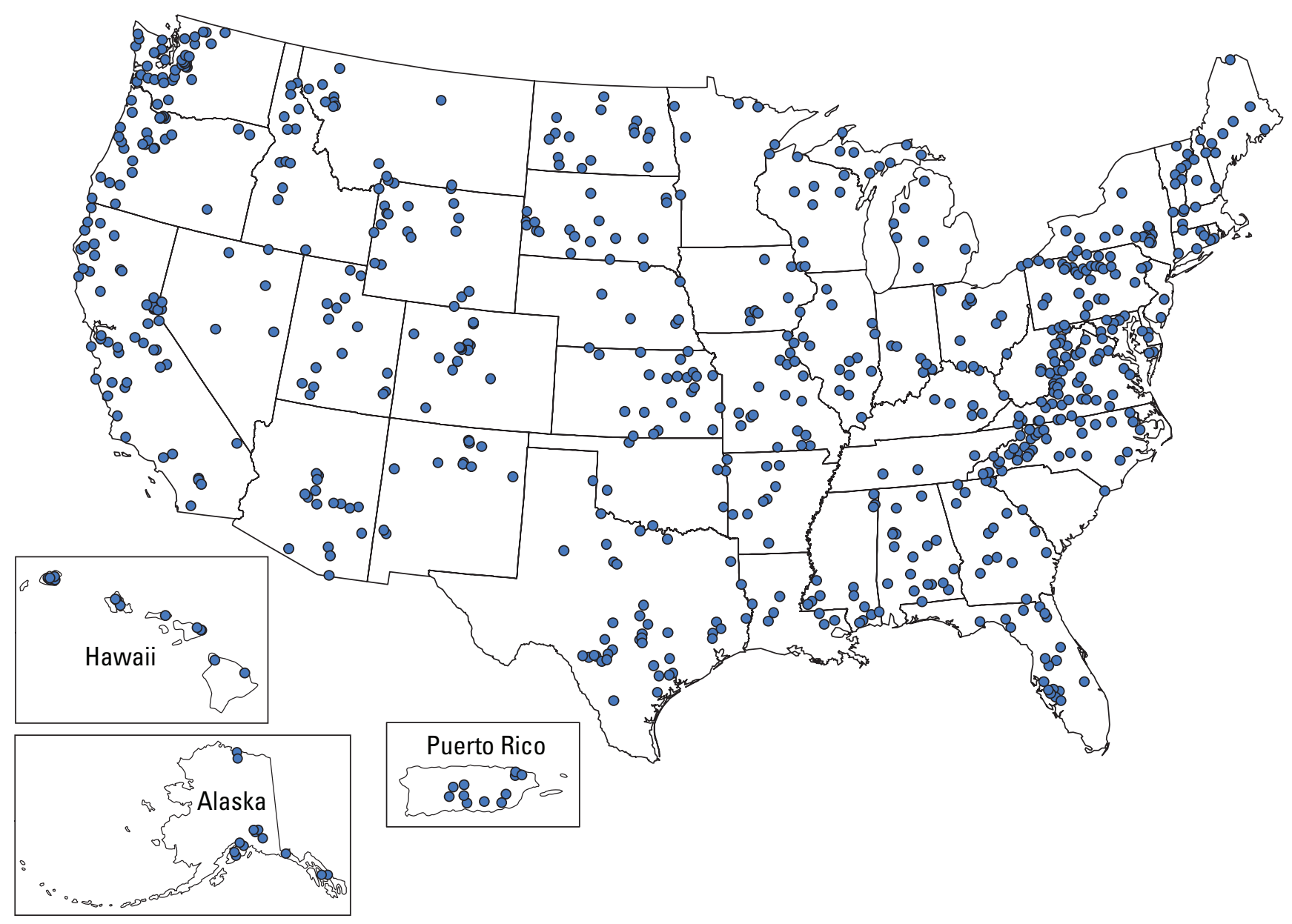

Figure 1. Location of the $743 \mathrm{HCDN}-2009$ stations by State and territory. 
U.S. boundaries, and watershed size is limited to $50,000 \mathrm{~km}^{2}$. Future updates of the HCDN will occur periodically and will be designated by the year for which the most recent quality assured and validated data are available.

HCDN-2009 is composed of 743 stations, and their geographic distribution is shown in figure 1 . Records cumulatively span the period 1898-2009 and contain a total of 41,292 water years ${ }^{1}$ of complete data. There are 594 stations having at least 40 years of record through the end of water year 2009, 302 with at least 60 years, 107 with at least 80 , and 4 with at least 100 years (fig. 2). The 10-year period 1960-1969 experienced the largest gain in stations, with 162 , while the preceding two decades (1950-1959 and 1940-1949) were second and third, respectively, with an increase of 114 and 110 (fig. 3). Nearly two-thirds of the 743 stations (471) began operation during the 40-year period 1930-1969.

\footnotetext{
${ }^{1}$ Water year is the period October 1 to September 30 and is designated by the year in which the period ends.
}

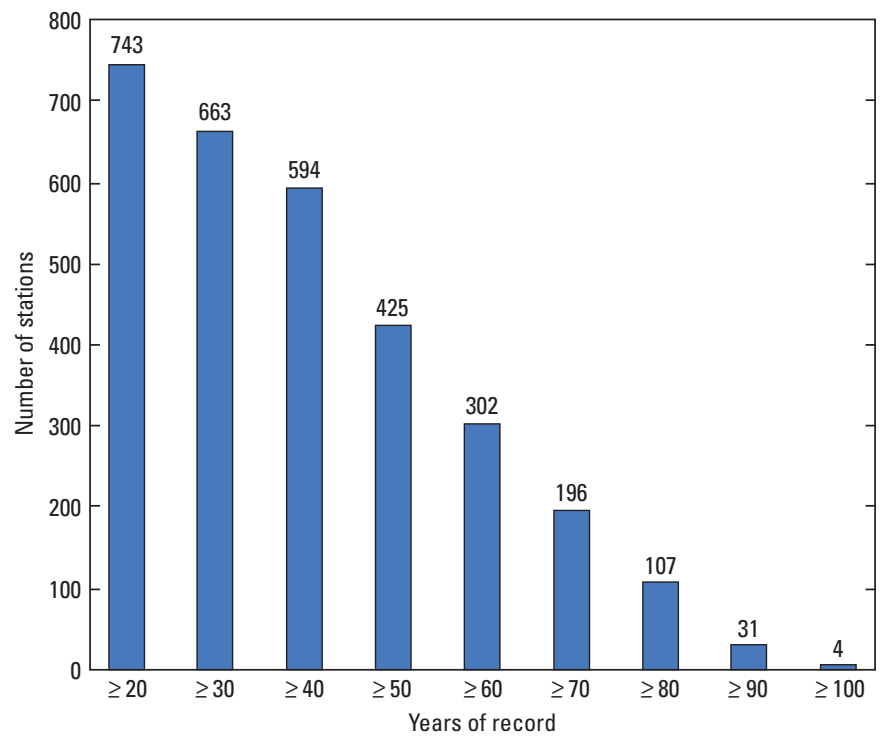

Figure 2. Number of HCDN-2009 stations grouped by number of years with complete record ending in 2009. All stations have at least 20 years of both complete $(365+$ days in a year) and continuous (unbroken) record ending in 2009.
Although the USGS has published HCDN-2009 as the listing of stations conforming to clearly defined criteria reflecting a dominant sensitivity to weather and climate (that is, the least sensitivity to confounding human activities), it also acknowledges that all streamgages reflect, to varying degrees, sensitivity to meteorological conditions. Thus, there are likely many stations that, although not passing the screening for inclusion in HCDN-2009, are nonetheless acceptable for use in climate-related hydrologic studies. Researchers may, therefore, wish to evaluate other stations for use in their studies, particularly in areas where there are few HCDN-2009 stations. Care should be exercised in doing so, however, especially for studies focused on low streamflow, where relatively small perturbations associated with human activities can have a significant effect on the observed discharge. For detailed information regarding the character and quality of individual USGS streamgages, please contact the relevant State USGS Water Science Center.

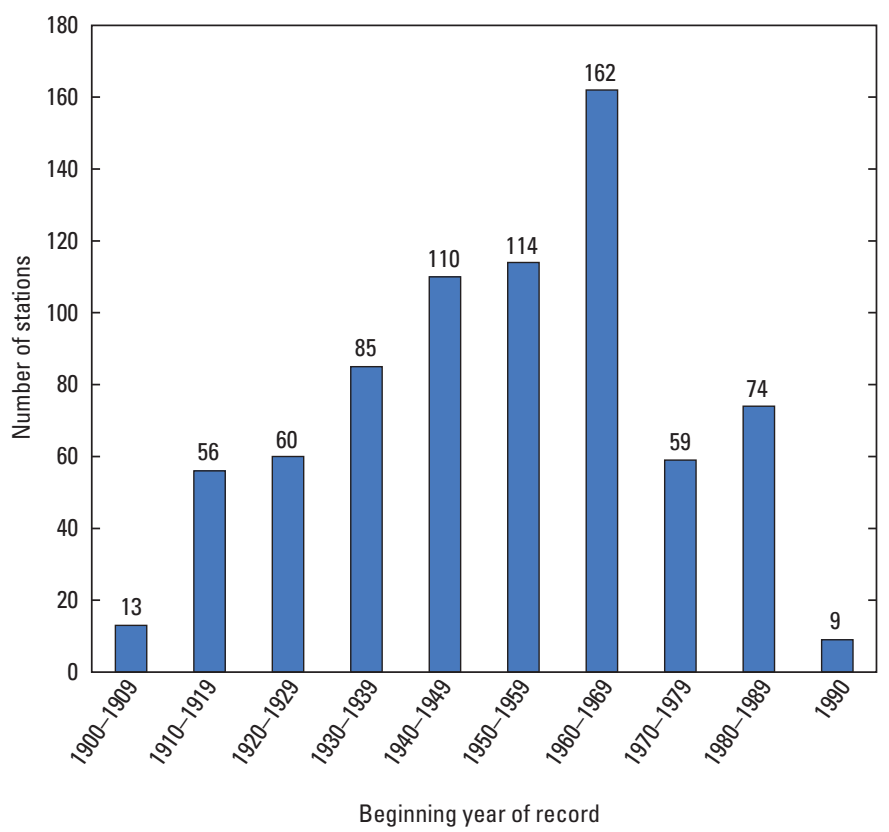

Figure 3. Number of HCDN-2009 stations grouped by the 10-year period when records were first collected. 
Details about the stations comprising the HCDN-2009 are available online at http://water.usgs.gov/osw/hcdn-2009/. The Web site has links to the interface of the USGS National Water Information System (NWISWeb) for retrieving streamflow data, and to the spatial data for the GAGES-II stations (including HCDN-2009). The latter includes a point shapefile of all 9,322 GAGES-II sites with summary attributes, a spreadsheet of the basin characteristics and variable descriptions, shapefiles of the basin boundaries, and Arc line coverages of the mainstem streamlines.

\section{References Cited}

Falcone, J.A., 2011, GAGES-II, Geospatial Attributes of Gages for Evaluating Streamflow [digital spatial dataset], available at http://water.usgs.gov/GIS/metadata/usgswrd/XML/ gagesII_Sept2011.xml.

Falcone, J.A., Carlisle, D.M., Wolock, D.M., and Meador, M.R., 2010, GAGES: A stream gage database for evaluating natural and altered flow conditions in the conterminous United States: Ecology, v. 91, no. 2, p. 621, a data paper in Ecological Archives E091-045-D1, available at http://esapubs.org/ Archivelecol/E091/045/metadata.htm.

Slack, J.R., and Landwehr, J.M., 1992, Hydro-climatic data network-A U.S. Geological Survey streamflow data set for the United States for the study of climate variations, 1874-1988: U.S. Geological Survey Open-File Report 92-129, 193 p.

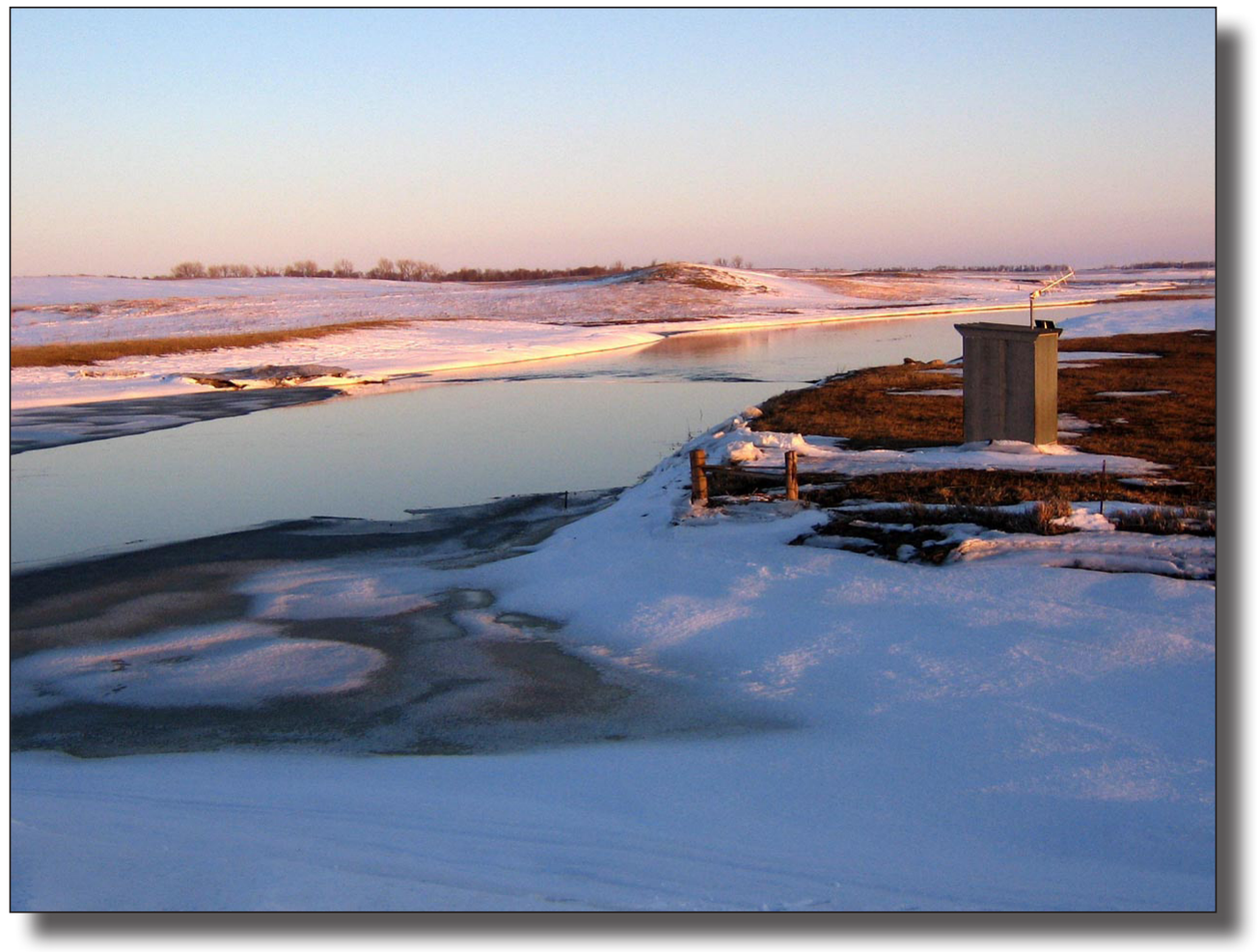

An HCDN-2009 site, Bear Creek near Oaks, North Dakota, USGS station 06470800, April 2, 2009. 